\title{
CONFORTABILIDADE DA UNIDADE DE PEDIATRIA: PERSPECTIVA DE USUÁRIOS, PROFISSIONAIS E GESTORES DE ENFERMAGEM
}

\section{COMFORTABLENESS OF PEDIATRIC UNIT: PERSPECTIVE OF USERS, NURSING PROFESSIONALS AND NURSING MANAGERS}

\section{CONFORTABILIDAD DE LA UNIDAD PEDIÁTRICA: PERSPECTIVA DE USUARIOS, PROFESIONALES $Y$ GESTORES DE ENFERMERÍA}

Juliane Portella Ribeiro ${ }^{1}$, Giovana Calcagno Gomes ${ }^{2}$, Bruna Bubolz Oliveira ${ }^{3}$, Fabiane Voss Klemtz ${ }^{3}$, Patrícia Pedrotti Soares ${ }^{3}$, Priscila Arruda da Silva ${ }^{4}$

\section{RESUMO}

Objetivo: analisar a confortabilidade da unidade de pediatria na perspectiva de usuários, profissionais e gestores de enfermagem. Método: estudo descritivo e exploratório, com abordagem qualitativa, realizado com usuários, profissionais e gestores de enfermagem. A coleta de dados ocorreu nas unidades de pediatria de dois Hospitais Universitários, por meio de entrevista semiestruturada e de foto-elicitação. Posteriormente, foram organizados e tratados pelo software Nvivo 10. Os dados foram submetidos à Análise Temática. Resultados: o mobiliário e estrutura física proporcionam, minimamente, conforto para a criança internada e o familiar que a acompanha; entretanto, a existência de brinquedoteca, as ações desenvolvidas por voluntários e a relação estabelecida com a equipe de enfermagem desde o acolhimento contribuem para a sensação de bem-estar e proporcionam tranquilidade. Conclusão: tendo em vista que os desafios envolvem aspectos estruturais, faz-se imperativo, o investimento no potencial das relações estabelecidas entre os trabalhadores de enfermagem, às crianças e seus familiares, para tornar a pediatria um ambiente confortável.

Descritores: Ambiente de instituições de saúde; Humanização da assistência; Pediatria; Criança hospitalizada; Enfermagem.

\begin{abstract}
Objective: to analyze the comfortableness of pediatric unit from the perspective of users, nursing professionals and nursing managers. Method: descriptive and exploratory study, with a qualitative approach, performed with users, nursing professionals and nursing managers. Data collection took place in the pediatric units of two university hospitals through semi-structured interviews and photo-elicitation. Subsequently, they were organized and handled by the Nvivo 10 software. The data were submitted to Thematic Analysis. Results: furniture and physical structure provide, minimally, comfort for the hospitalized child and the family member accompanying them; however, the existence of a toy library, the actions developed by volunteers and the relationship established with the nursing staff since the reception contribute to well-being and provide tranquility. Conclusion: considering that the challenges involve structural aspects, it is imperative to invest in the potential of established relationships between nursing workers and children and their families, aiming at making the pediatric unit a comfortable environment. Descriptors: Health facility environment; Humanization of care; Pediatrics; Hospitalized child; Nursing.
\end{abstract}

\section{RESUMEN}

Objetivo: analizar la confortabilidad de la unidad pediátrica en la perspectiva de usuarios, profesionales y gestores de enfermería. Método: estudio descriptivo y exploratorio, con planteamiento cualitativo, efectuado con usuarios, profesionales y gestores de enfermería. La recolección de datos ocurrió en las unidades pediátricas de dos Hospitales Universitarios mediante entrevistas semiestructuradas y de foto-elicitación. Posteriormente, los datos fueron organizados y tratados con el software Nvivo 10. Los datos fueron sometidos al Análisis Temático. Resultados: el mobiliario y la estructura física proporcionan mínimamente confort para el niño hospitalizado y el familiar que lo acompaña; sin embargo, la existencia de ludotecas, las acciones desarrolladas por voluntarios y la relación establecida con el equipo de enfermería desde la acogida contribuyen a la sensación de bienestar y proporcionan tranquilidad. Conclusión: considerando que los desafíos involucran aspectos estructurales, se hace imperativa la inversión en el potencial de las relaciones establecidas entre los trabajadores de enfermería, los niños y sus familiares para hacer de la pediatría un ambiente confortable.

Descriptores: Ambiente de instituciones de salud; Humanización de la asistencia; Pediatría; Niño hospitalizado; Enfermería.

${ }^{1}$ Graduada em Enfermagem. Doutora em Enfermagem pela Universidade Federal do Rio Grande. Docente na Universidade Federal de Pelotas. ${ }^{2}$ Graduada em Enfermagem. Doutora em Enfermagem pela Universidade Federal de Santa Catarina. Docente na Universidade Federal do Rio Grande. ${ }^{3} \mathrm{Graduanda}$ em Enfermagem pela Universidade Federal de Pelotas. ${ }^{4}$ Graduada em Enfermagem. Doutora em Enfermagem pela Universidade Federal do Rio Grande.

Como citar este artigo:

Ribeiro JP, Gomes GC, Oliveira BB, et al. Confortabilidade da Unidade de Pediatria: Perspectiva de Usuários, Profissionais e Gestores de Enfermagem. Revista de Enfermagem do Centro-Oeste Mineiro. 2018;8:e2055. [Access

https://doi.org/10.19175/recom.v7i0.2055 


\section{INTRODUÇÃO}

O cuidado em pediatria suscita a promoção de um ambiente que atenda às necessidades da criança, por meio de um olhar diferenciado, que pondere a especificidade desta fase da vida, em que se tem maior dificuldade em lidar com o adoecimento, e enfrentar o desconhecido e o medo causado por ele. Além de estar fora de casa, geralmente ela está fragilizada física e emocionalmente, carecendo de conforto que este ambiente, com limitadas dimensões, nem sempre oferece $^{(1)}$.

Estudo com objetivo de compreender a hospitalização pelo olhar da criança e do adolescente internados em uma unidade pediátrica, revelou um aspecto ambíguo, pois embora o hospital seja considerado pelos participantes como lugar de cura e cuidados, os mesmos expressam sentimento de tristeza, medo, prisão, saudade dos amigos, irmãos e parentes. Além disso, sentem falta de brincar, o que parece aumentar a solidão e a insegurança que vivenciam nesta experiência ${ }^{(2)}$.

Observa-se que, mesmo com a existência de unidades pediátricas, específicas para internação de crianças, as experiências negativas advindas com a hospitalização não são suavizadas, pois, geralmente, a carência de material e equipamentos, somados à diversidade de profissionais que prestam assistência, dificultam a construção de uma ambiência acolhedora e estruturada para assistir a criança de forma integral e humana. Como resultado, observamos a tendência à massificação e padronização das ações, tornando a assistência mecânica e previsível(3).

Não raro, essa situação acarreta frustração dos profissionais, ao perceberem que as dificuldades vivenciadas no ambiente hospitalar poderão prolongar o período de internação da criança e, até mesmo, ocasionar um sofrimento maior, por não dispor de todos os recursos necessários para cuidá-la ${ }^{(4)}$. Além disso, os profissionais são confrontados com sentimento de empatia pela criança, associando-a aos próprios filhos ou parentes, devido ao sofrimento de ver alguém tão jovem passando pelo enfrentamento do adoecimento, ao comportamento habitual da criança de chorar para demonstrar medo e dor, ao desespero dos pais pela realidade do filho doente e da impotência diante do agravo ${ }^{(5)}$.
Assim, faz-se necessário articular esforços no sentido de superar tais condições ambientais que, além de ocasionar sofrimento à criança e sua família, também incide em frustração nos profissionais de saúde. Cabe, portanto, aos gestores, investir em questões fundamentais como adequação do ambiente de pediatria com equipamentos e tecnologias que considerem e respeitem a singularidade das necessidades tanto dos usuários quanto dos profissionais ${ }^{(6)}$.

Estudo que avaliou a satisfação dos profissionais de um hospital pediátrico municipal de Fortaleza quanto ao cuidado humanizado constatou que o ambiente era percebido como confortável para o exercício de suas funções, mas com necessidade de melhoria. Embora a maioria dos respondentes tenha avaliado a aparência do hospital como satisfatória, $47 \%$ indicaram a necessidade de reforma, considerando que o mesmo não apresentava estrutura apropriada ao atendimento de sua clientela ${ }^{(7)}$.

Constata-se que os esforços em construir um ambiente hospitalar voltado para a criança encontram barreiras desde a concepção, visto que os espaços de saúde, muitas vezes, refletem as decisões de um arquiteto e do pequeno número de dirigentes acerca da configuração ideal. Sem pautar-se nas regras e normas padronizadas pelos órgãos competentes e no cotidiano da Unidade de Pediatria, torna-se provável encontrar inadequações no ambiente, que dificultam o uso e apropriação do mesmo pela criança, família e profissionais da enfermagem e da saúde.

Nesse sentido, é imperativa a observância de elementos que atuem como modificadores e qualificadores da unidade de pediatria, potencializando a construção de um ambiente confortável, que contribua significativamente para a mudança na percepção do hospital como um ambiente frio e hostil ${ }^{(8)}$. Diante do exposto, o presente estudo teve por objetivo, analisar a confortabilidade da unidade de pediatria na perspectiva de usuários, profissionais e gestores de enfermagem.

\section{MÉTODO}

Trata-se de um estudo descritivo e exploratório com abordagem qualitativa, realizado na Unidade de Pediatria de dois Hospitais Universitários do sul do Brasil. Participaram do estudo 20 usuários, 20 profissionais de enfermagem (com 
representantes dos diferentes turnos de trabalho: manhã, tarde e noite) e 04 gestores, totalizando 44 participantes.

O anonimato dos participantes foi preservado por meio do emprego das letras " $U$ " para os usuários, " $E$ " para os trabalhadores de enfermagem e "G" para os gestores, sucedidos de algarismos arábicos que indicam o número da entrevista. Já, os ambientes investigados, foram identificados como "HA" e "HB".

A coleta de dados ocorreu no segundo semestre de 2014, por meio de entrevista semiestruturada e da foto-elicitação, que trata-se de uma abordagem que tem por objetivo utilizar fotografias no decorrer de uma entrevista semiestruturada para evocar comentários, memórias e discussões ${ }^{(9)}$. Para preservar o conteúdo original e aumentar a acurácia dos dados obtidos, as entrevistas foram capturadas por um gravador de áudio.

Para a organização e tratamento dos dados, empregou-se o software Nvivo 10, programa que auxilia na análise de material qualitativo, com ferramentas de codificação e armazenamento de textos $^{(10)}$. Sendo, posteriormente, analisados e categorizados conforme a Análise Temática proposta por Minayo ${ }^{(11)}$.

Foram seguidos os preceitos éticos para realização da pesquisa envolvendo seres humanos, conforme a Resolução no 466 , de 12 de dezembro de 2012. Considerando que, eventualmente, os sujeitos da pesquisa foram fotografados durante a coleta de dados, as implicações éticas e legais que envolvem o uso da imagem foram trabalhadas no Termo de Consentimento Livre e Esclarecido (TCLE), observando-se a Constituição Federal, em seu artigo 5o, incisos X e XXIII, e Código Civil em seu artigo 11 e seguintes ${ }^{(12)}$. Além disso, o anonimato dos sujeitos participantes foi preservado por meio de editor de imagem, que possibilitou desfocar os rostos das fotos, retirando sua nitidez.

O projeto foi encaminhado ao Comitê de Ética em Pesquisa da Área da Saúde da Universidade Federal do Rio Grande (CEPAS/FURG) e aprovado mediante o Certificado de Apresentação para Apreciação Ética (CAEE) no 31172914.6.0000.5324, recebendo parecer favorável para sua publicação sob Parecer no 85/2014.

\section{RESULTADOS E DISCUSSÃO \\ Confortabilidade da unidade de pedriatria}

A partir da organização e análise dos dados, revelaram-se como categorias relevantes à confortabilidade da unidade de pediatria: o mobiliário, a estrutura física, a brinquedoteca, a estética da unidade e o acolhimento da equipe de enfermagem.

\section{Mobiliário}

Os participantes apontam que o ambiente de pediatria apresenta conforto à criança, entretanto, reconhecem a existência de limitações em relação ao mobiliário, o que suscita empenho em adequá-lo ao seu usuário: "Para a criança, tem a cama adequada para o tamanho dela, a gente sempre tenta colocar uma cama adequada ao tamanho dela para ficar confortável” (E3_HB). “Esses berços já são bastante ultrapassados. Hoje existem camas automáticas, que são camas para pediatria com barra lateral de segurança" (G1_HB).

Os entrevistados referem que, para $\mathrm{O}$ familiar cuidador, o conforto resume-se à oferta de uma cadeira próxima ao leito da criança. Entretanto, a mesma não atende às suas necessidades de conforto, principalmente em internações por longos períodos: "Conforto é assim, te dão uma cadeira para sentar e tu tens que passar um mês, dois. $O$ que é uma cadeira para passar um mês, dois" (U8_HB).

As cadeiras mostram-se inviáveis aos familiares cuidadores no turno da noite, visto que não permitem aos mesmos deitarem. Assim, a postura adotada para o descanso noturno acarreta dores e desconforto: "A gente dorme na poltrona, então é complicado, a gente fica meio tortinha, com dor na coluna. Tu olhas, assim, de dia ela é maravilhosa, mas chega à noite, dói tudo" (U1_HA). "A mãe fica mal acomodada numa cadeira, não tem uma cama para descansar" (E8_HB). "[...] a mãe não tem tanto conforto, porque é uma poltrona que está um pouco estragada elas ficam mal acomodadas para dormir" (E4_HA). "Se é obrigatório ter um acompanhante eu não posso deixar ela ali um ano dormindo na cadeira, à noite" (G1_HB).

Ainda com relação ao mobiliário, os usuários apontam a necessidade de armários maiores para acomodar seus pertences. Além disso, os armários existentes deixam os familiares receosos e com medo, uma vez que apresentam risco de acidente, por se tratarem de armários aéreos e sem portas, fixados acima do leito da criança: "Tinha que ter um armário para colocar tuas roupas, tuas coisinhas, porque as minhas estão tudo aqui no chão, dentro de sacola. Falta espaço" (U7_HB). "Eu acho um perigo aqueles 
armários que nem armário é. É uma prateleira que tem em cima da cama das crianças com dois parafusos que tá arriscando a cair em cima da criança, eu fiquei com medo" (U8_HA).

Para superar as restrições relativas à mobília e proporcionar bem estar à criança, a disponibilização de televisores na enfermaria é apontada como recurso que atende ao gosto da criança e resgata uma atividade realizada no âmbito domiciliar: "Vê uma televisão, que eles estão fora de casa muito tempo e eles gostam de ver TV é muito importante" (E4_HA). "Se fosse possível, eles gostam muito de televisão dentro do quarto" (E7_HB). "Deveria ter no quarto uma televisão. Seria bastante importante para entreter a criança" (U9_HA).

Diante de tais achados, é imperativa a observância de que o Estatuto da Criança e do Adolescente (ECA), de 1990, que em seu capítulo I - Direito à Vida e à Saúde - preconiza que os serviços de saúde deverão proporcionar condições para a permanência dos familiares, em tempo integral, nos casos de internação de criança $^{(13)}$. Enfatizando que, não basta garantir o direito da criança de ter um acompanhante, é preciso que existam espaços capazes de acolhêlos, nos diversos ambientes da unidade, de forma que eles possam também ter momentos de encontros, diálogos, relaxamento e entretenimento, como assistir à televisão ou ouvir música ${ }^{(8,14)}$.

Pesquisadores apontam que, quando o ambiente hospitalar está adaptado e oferece apoio, a presença do familiar é um importante contribuinte para a sensação de conforto e bemestar na criança, semelhante à experiência de estar em casa. Assim, gradualmente, auxiliando-a na aceitação e adaptação à doença, bem como, na participação ativa em seu tratamento ${ }^{(15)}$.

Diante das preconizações legais e dos benefícios acarretados pela permanência do familiar no ambiente hospitalar, faz-se necessário que as instituições investigadas proporcionem melhores instalações e mobiliário aos mesmos, visto que, por ora, o conforto ofertado resume-se à disponibilização de poltrona ou cadeira reclinável, que independentemente ao período que o familiar permanece junto à criança, mostram-se inadequadas, principalmente à noite, pois não permite reclinar o corpo e deitar, causando dores que persistem ao longo do dia.

Da mesma forma, estudo realizado com mães de crianças hospitalizadas, evidenciou que o conforto ainda é privilégio das crianças, pois as acompanhantes ficam em poltronas que se tornam desconfortáveis após o primeiro dia de internação ${ }^{(16)}$. Outro estudo, que investigou os reflexos da hospitalização da criança na vida do familiar acompanhante, mostrou que a falta de uma estrutura física adequada ao seu repouso, acrescidas pela necessidade de se manter continuamente alerta a qualquer alteração na condição clínica da criança e as demandas específicas de cuidado, acarretam cansaço acentuado nos familiares ${ }^{(17)}$.

\section{Estrutura Física}

Com relação ao aspecto estrutural, os participantes enfatizam a questão do espaço, apontando que o número de leitos existentes compromete a acomodação do mobiliário, da criança e de seu familiar na enfermaria: "Eu tiraria várias pessoas do quarto. É apertado" (U3_HB). "Eu acho que deveria ter mais quartos com menos gente. No caso, com quatro camas seria mais espaçoso" (U10_HA). "A estrutura é muito pequena. As enfermarias possuem cinco leitos com espaço para quatro" (E1_HB). "Aqui mesmo, não tem espaço para a poltrona da outra cama. Tudo muito pequeno, muito apertado" (E1_HA).

Dentre as inadequações estruturais citadas, a falta de instalação de tubulação e saída de gases em quantidade suficiente para atender a todos os leitos constitui-se em desconforto, pois a criança e o seu acompanhante precisam deslocar-se pela enfermaria para acessá-los: "O oxigênio mesmo falta [...]; a criança fica lá no canto tem que tirar de lá para vir fazer nebulização. Então, não considero um ambiente confortável" (E9_HB). "Agora mesmo, a gente está com uma mãe que tem de ir lá ao outro leito para fazer nebulização, então ela tem que acordar de hora em hora e isso é muito frustrante para a mãe que está acompanhando" (E8_HA).

Igualmente, o banheiro das enfermarias carece de atenção em relação à sua estrutura, pois não possuem qualquer adaptação para atender ao seu público alvo, as crianças: "Ele não está estruturado para criança, e sim para adulto" (U2_HB). "Só tem vaso sanitário e pia para adulto, não são adequados para as crianças. Quando fizeram, fizeram pensando só nos adultos" (E9_HA).

Ademais, a forma como o banheiro está arquitetado dificulta sua utilização por crianças com necessidades especiais como os cadeirantes: "O banheiro teria que ser maior, para uma 
criança cadeirante, ele se torna apertado" (U2_HB). "A estrutura não permite que entremos com cadeiras de rodas dentro dos banheiros, aqui a estrutura não nos favorece" (E6_HA).

A falta de estrutura dos banheiros faz com que os familiares cuidadores improvisem estratégias para realizar a higiene das crianças menores, que necessitam utilizar banheira e trocador: "O banho, a gente dá em cima da poltrona. Aqui, no banheiro, poderia fazer um espacinho ou botar um trocador, porque aí eu dava banho no banheiro" (U7_HA).

Faz-se imprescindível atentar para a forma como o ambiente de pediatria está arquitetado. Especificamente em relação ao espaço físico, a unidade pediátrica deve atender às normas estabelecidas pela Agência Nacional de Vigilância Sanitária(18) e Associação Brasileira de Normas Técnicas ${ }^{(19)}$. Esses órgãos estabelecem a estrutura de uma enfermaria em relação ao número de leitos, tamanho de quartos, distância entre os leitos, isolamentos, além de outras especificações acerca desse quarto ou enfermaria, como lavatório, pia, acabamentos, piso, teto, banheiros, iluminação, gases medicinais, tomadas, portas e janelas, banheiros, mobília, corredores, sinalização e acessibilidade ${ }^{(5)}$.

De encontro a tais normas, as unidades investigadas apresentam inadequações em sua estrutura, tais como: falta de instalação de tubulação e saída de gases em quantidade suficiente para atender a todos os leitos; banheiros que não possuem adaptação para o público atendido na unidade; quantidade de leitos nas enfermarias que compromete a acomodação do mobiliário, da criança e de seu familiar na enfermaria; higienização precária da unidade, que contribui para existência de moscas e mau odor no ambiente.

Além de não atender às normas supracitadas, as inadequações apontadas na estrutura das pediatrias contrariam as determinações do Estatuto da Criança e do Adolescente, que prevê, entre outras determinações, que as instituições de internação devem oferecer atendimento personalizado, em pequenas unidades e grupos reduzidos, com instalações físicas em condições adequadas de habitabilidade, higiene, salubridade e segurança, promovendo um ambiente de respeito e dignidade à criança e ao adolescente, bem como, preserve os seus vínculos familiares ${ }^{(14)}$.

\section{Brinquedoteca}

As unidades pesquisadas contam com a brinquedoteca como espaço de recreação para as crianças, que transcende os horizontes da enfermaria e permite a elas brincarem e realizarem atividades próprias à sua idade, sob a supervisão profissional: "As crianças têm acesso à sala de recreação em tempo integral, direcionada em determinados horários quando a pedagoga acompanha. A ludoterapia é extremamente importante porque a criança, diferentemente do adulto, não foca na doença. Se tu ofereceres à criança brinquedos ou algo que a distraia ela vai viver aquilo ali. Não vai lembrar o doloroso do procedimento. Isso também deve ser visto, propiciando que a criança tenha vida de criança" (G1_HA). "As crianças adoram porque lá eles vão pintar, fazer brincadeiras, tem o pessoal da psicologia e artes visuais, tem brinquedos, faz parte da terapia" (E10_ HB). "É uma distração para ele. Ele pode vir aqui brincar, se distrair um pouquinho e passar as horas. Eles não ficam sem poder brincar. Criança gosta muito de poder brincar" (U3_HA).

Esse espaço, além de entreter a criança, propicia, ao familiar acompanhante, momentos de descanso e descontração, modificando a rotina centrada no cuidado à criança: "Para as crianças, é muito importante e para a família também. Tem mãe que fica sozinha e o pouco tempo de descanso que tem é quando a criança está ali" (E4_HA). "Com a brinquedoteca, a mãe tem um descanso naquele momento em que a criança está lá dentro brincando, é uma trégua. Muda um pouquinho a rotina, aquele compromisso de sempre estar olhando a criança. Para ambos é um momento de descontração" (E2_HB). "Bom, muitos brinquedos para a criança brincar, para se entreter. Para mim é bom, eu vou lá para esfriar a cabeça" (U5_HB).

Outro recurso apontado como promotor de confortabilidade são as ações realizadas por voluntários. Essas ações modificam a pediatria, promovendo uma ambiência alegre e harmônica, sendo perceptível o contentamento das crianças, dos familiares e profissionais de enfermagem: "Muito gratificante, eu gosto de música, que alguns senhores que vem cantar, deixa 0 ambiente mais alegre, não só para as crianças, mas para nós também" (E9_HA). "Toda sextafeira a oficina da alegria está aí. Tem um menino que dizem que está em estado vegetativo, mas nesse dia ele fica bem diferente. Vieram e cantaram para ele as musiquinhas e tu vês a 
diferença, a reação da criança. É bom, quem não gosta de música? Todo mundo gosta" (E10_HB). "Isso aqui é muito bom, porque a criança passa aqui dentro um momento difícil, um momento de dor. $O$ familiar também sofre junto com a criança e eles vêm e trazem um momento de alegria para o paciente e para a família, muito bom" (U8_HA).

Diante dos relatos, constata-se que a brinquedoteca é um espaço de recreação, que transcende os horizontes da enfermaria, permitindo que a criança brinque e realize atividades próprias à sua idade, assim, distraindoa da rotina hospitalar e aproximando-a do universo infantil. À medida que o cuidado incorpora a atividade lúdica, modifica o processo de produção de saúde e constrói uma nova ambiência, menos estressante e mais humana à criança.

Ao encontro desse resultado, pesquisa realizada com crianças hospitalizadas indicou que a brinquedoteca possibilita maior aceitação da situação vivenciada, melhor adaptação e familiarização ao ambiente, transformando o hospital em algo familiar e mais agradável, onde se pode conhecer outras crianças e, juntas, praticarem a atividade tão essencial para 0 desenvolvimento infantil que é o brincar ${ }^{(20)}$.

Evidencia-se que, para os gestores, há preocupação em garantir a conformidade às normas regulamentadoras, adaptando o espaço às necessidades e especificidades da população atendida. De acordo com a Lei no 11.104, de 21 de março de 2005 , é obrigatória a instalação de brinquedotecas nas unidades de saúde que ofereçam atendimento pediátrico em regime de internação(21). Embora essa obrigatoriedade seja um grande avanço para as políticas públicas, há ainda alguns desafios a serem superados, como adequação do espaço e estabelecimento de uma rotina de funcionamento ${ }^{(20)}$.

Outro recurso promotor de confortabilidade são as ações realizadas por voluntários, como a palhaçoterapia, que modificam a pediatria, promovendo uma ambiência alegre e harmônica, sendo perceptível o contentamento das crianças, de seus familiares e dos profissionais de enfermagem. Resultado semelhante a este foi evidenciado por um estudo realizado com crianças internadas em hospitais da Suécia, o qual mostrou que o encontro com o palhaço constrói um espaço mágico e seguro, capaz de proporcionar relaxamento e a sensação de alegria, proporcionando uma certa distância da hospitalização ${ }^{(22)}$.

\section{Estética da unidade}

Para que as unidades pesquisadas de fato se caracterizem como pediatria, espaço para o tratamento de crianças, os entrevistados sugerem a utilização de pinturas, desenhos, brinquedos e televisores, aspectos que resgatam o universo infantil, minimizando o sofrimento e tornando-o agradável às crianças: "A cor tem que ser diferente, tem que ser mais clarinha, uma cor que tu identificasses que é uma pediatria" (U8_HB). "Eu deixaria mais colorido isso aqui. Botava uma TV para eles se entreterem, uns brinquedos" (U6_HA). "Falta alguma coisa aqui, falta alguma coisa que tu diz: estou no setor pediátrico. Eu mudaria o tom das paredes colocaria desenhos aqui, já daria outra aparência, quando olhasse saberia que é pediátrico" (E5_HA).

A mudança estética na unidade de pediatria, com a inclusão de desenhos e personagens infantis, é expressa como um recurso a ser utilizado na confortabilidade, pois, além de ser um tratamento ao ambiente, embelezando-o, também é tido pelos gestores como auxiliar na redução da dor e estresse da criança, por conseguinte, proporcionando tranquilidade à família: "Um ambiente físico que seja agradável, onde você tenha alguma coisa visual para que essa criança se sinta à vontade é muito importante. Eu já coloquei uma vez numa pediatria uns adesivos de parede, que são hospitalares, ficaram um encanto. Cada parede tinha uma imagem de um desenho da televisão, Sininho, Peter Pan e ficaram show de bola, as enfermarias. Então, ali a criança se sente num outro espaço, num outro ambiente. Isso diminui a dor, o estresse e, consequentemente, a mãe consegue ficar mais tranquila, porque a criança se sente melhor" (G1_HB).

Os participantes da pesquisa sugerem adequações na estética das unidades, com a utilização de pinturas, com desenhos e personagens infantis, brinquedos e televisores, de forma a caracterizá-las como pediatrias, espaços próprios para o tratamento de crianças. Ao resgatar o universo infantil, reduzem-se as referências ao ambiente hospitalar e aproxima-se a pediatria ao ambiente domiciliar, tornando-a agradável às crianças.

Pesquisa desenvolvida em um Hospital Infantil de Sydney, Austrália, demonstrou que a estética agradável do local, com pinturas, fotografias e esculturas confeccionadas pelas próprias crianças internadas, contribuiu para aliviar o estresse emocional ocasionado pela 
hospitalização, constituindo-se em uma fonte de entretenimento e distração. Sem parecer-se com um hospital, o mesmo oportunizou a elas sentirem-se em ambiente construído para crianças $^{(23)}$.

Neste sentido, adequar a ambiência da pediatria contribui para a construção de novas situações, em que promover a saúde não se restringe à ordem curativa e à redução do tempo de permanência no hospital, mas sim, à necessidade de auxiliar a criança a atravessar a situação de hospitalização com mais benefícios que prejuízos ${ }^{(1)}$.

Estudo realizado com crianças de 6 a 12 anos, cujo objetivo foi investigar suas experiências e necessidades ambientais, mostrou que o ambiente de tratamento desejado pelas mesmas envolve entretenimento e atividades recreativas, decoração e cores alegres, espaço coletivo para interação com os demais, luz e ambiente natural, que proporcionem uma sensação de segurança. Apontando que realizar adequações nesse sentido, além de contribuir para a confortabilidade, podem acelerar o processo de reabilitação infantil ${ }^{(24)}$.

\section{Acolhimento da equipe de enfermagem}

Os respondentes apontam a relação com a equipe de enfermagem, estabelecida desde o acolhimento na unidade, como aspecto contribuinte para a sensação de bem-estar e tranquilidade no ambiente de pediatria: "Primeira coisa que tem que ter é a parte da enfermagem, acolher bem, para ter um ambiente bem tranquilo, ainda mais que é com criança. Tu já estás aqui por uma situação complicada, então tu tens que te sentires bem no ambiente que está $\mathrm{s}$, eles te acolhem bem, te recebem bem, acho que isso é importante" (U8_HB). "Fui muito bem acolhida, nas duas vezes que meu filho esteve aqui. Eu vi como era o tratamento deles com as crianças. Os profissionais são muito queridos, muito educados. Te dão tranquilidade. Tu sabes que eles estão bem cuidados" (U1_HA).

Nesse sentido, os gestores evidenciam que, para a unidade de pediatria ser percebida pelos usuários como um ambiente capaz de acolhê-los e responder às suas variadas demandas de forma integral, faz-se necessário a existência de recursos materiais, agregar saberes e valorizar as relações: "O ambiente da pediatria tem que ser um ambiente acolhedor, que dê conta da necessidade tanto técnica quanto humana, porque eu entendo que as crianças, assim como todos os seres humanos, têm multidimensões biopsicossociais e espirituais. Esse ambiente tem que atender à necessidade física e tem que atender a essas outras necessidades. Então, ele precisa ser um ambiente humanizado, ou seja, que atenda o indivíduo na sua integralidade. Para isso, é preciso que tenha toda a questão técnica, aquela tecnologia dura para atender as necessidades físicas, as tecnologias leveduras, os protocolos, porque não se pode fazer nada sem protocolo, sem ter evidência científica, porque a gente está lidando com vidas. E precisa ter as tecnologias leves, que são as relações, as quais são extremamente importantes, para atender essas necessidades psíquicas e espirituais" (G2 HA).

Os profissionais expressam a preocupação com o fato de que dificuldades estruturais existentes possam interferir no ambiente relacional e, consequentemente, no acolhimento, na formação de vínculo e de confiança entre os profissionais da saúde e família, na adesão ao tratamento e continuidade de cuidados à saúde da criança: "Temos dificuldade aqui no hospital devido à estrutura física mas, dentro do que podemos oferecer, nós temos muita preocupação de fazer com que esse ambiente seja acolhedor. Isso é extremamente importante para a adesão ao tratamento, para criar vínculo, confiança no profissional por parte da família e confiança na família partindo do profissional, para dar continuidade à saúde dessa criança" (E4_HA).

Os resultados apontam que a confortabilidade sustenta-se pelo acolhimento na unidade de pediatria. Portanto, a forma como a equipe de enfermagem interage com a criança e seu familiar, desde o acolhimento, contribui para a sensação de bem-estar. Ressaltando, assim, que o cuidado se concretiza no estar com o outro, pelo gesto de acolhida, pela atenção e envolvimento ${ }^{(25)}$.

\section{CONSIDERAÇÕES FINAIS}

Os resultados apontam que a confortabilidade da unidade de pediatria envolve o mobiliário, a estrutura física, a brinquedoteca, a estética da unidade e o acolhimento da equipe de enfermagem. Evidenciou-se que as unidades estudadas apresentam limitações em relação ao mobiliário e estrutura física ofertados à criança internada e ao familiar que a acompanha; entretanto, a existência de brinquedoteca e as ações desenvolvidas por voluntários promovem um ambiente alegre e de entretenimento, que 
aproxima a pediatria do universo infantil. Além disso, a relação estabelecida com a equipe de enfermagem desde o acolhimento na unidade contribui para a sensação de bem-estar e proporcionam tranquilidade.

Diante desse contexto, emergem desafios a serem superados para que as unidades pediátricas se constituam em ambientes confortáveis, tais como modernização de mobiliários e equipamentos, ampliação do espaço ou redução da quantidade de leitos nas enfermarias, adaptação dos banheiros ao público atendido, inclusão de cores, brinquedos e decoração nas enfermarias. Constata-se que os desafios envolvem aspectos estruturais, o que suscita, portanto, maior investimento.

O presente estudo apresenta como limitação o fato de que seus dados não permitem generalização, pois retrata a realidade de pediatrias de dois Hospitais Universitários do Sul do Brasil, que possuem semelhanças históricas em relação à origem, envolvimento com ensino, pesquisa, extensão e assistência à saúde, logo, retratando as especificidades de uma dada região.

Faz-se imperativo a realização de novas pesquisas sobre a temática da confortabilidade, visto que não só a literatura científica como os meios de comunicação evidenciam, nos ambientes hospitalares, condições insatisfatórias que não atendem às necessidades dos usuários, dos trabalhadores e nem de gestores.

\section{REFERÊNCIAS}

1. Silva PLN, Xavier GC, Oliveira VV, Figueredo ML, Prado PF, Aguiar Filho Wilson. Câncer infantil: vivências de crianças em tratamento oncológico. Enferm Foco. 2016;7(3/4):51-5. https://doi.org/10.21675/2357-

\section{X.2016.v7.n3/4.916}

2. Gomes ILV, Queiroz MVO, Bezerra LLAL, Souza NPG. A hospitalização no olhar de crianças e adolescentes: sentimentos e experiências vivenciadas. Cogitare Enferm. 2012;17(4):703-9. https://doi.org/10.5380/ce.v17i4.30378

3. Boeger M. Hotelaria hospitalar: gestão em hospitalidade e humanização. São Paulo: Editora Senac; 2009.

4. Gomes ILV, Câmara NAC, Lélis GMD, Grangeiro GFC, Jorge MSB. Humanização na produção do cuidado à criança hospitalizada: concepção da equipe de enfermagem. Trab Educ Saúde.

2011;9(1):125-35.

\section{http://dx.doi.org/10.1590/S1981-}

\section{$\underline{77462011000100009}$}

5. Fonseca AS. Enfermagem Pediátrica. São Paulo: Martinari, 2013.

6. Ministério da Saúde (BR). Secretaria de Assistência à Saúde. Programa Nacional de Humanização da Assistência Hospitalar. Brasília, DF: Ministério da Saúde; 2001 [citado em 18 jun 2017]. (Série C. Projetos, programas e relatórios, Vol. 20). Disponível em: http://bvsms.saude.gov.br/bvs/publicacoes/pnha h01.pdf

7. Lima FET, Jorge MSB, Moreira TMM. Humanização hospitalar: satisfação dos profissionais de um hospital pediátrico. Rev Bras Enferm. 2006;59(3):291-6.

https://doi.org/10.1590/S003471672006000300008

8. Ministério da Saúde (BR). Secretaria de Atenção à Saúde, Núcleo Técnico da Política Nacional de Humanização. Ambiência. 2a ed. Brasília, DF:; 2010. Disponível em: http://bvsms.saude.gov.br/bvs/publicacoes/ambi encia 2ed.pdf

9. Salvagni J, Silveira MAN. Discursos imagéticos: a fotografia como método da pesquisa social. In: Anais Eletrônicos do II Encontro História, Imagem e Cultura Visual; 8-9 ago 2013. Porto Alegre, RS. Porto Alegre: PUC-RS; 2013. p. 1-8.

10.Ames VDB. As possibilidades de uso do software de análise qualitativa Nvivo. Sociologias Plurais. 2013;1(2):230-47.

11. Minayo MCS. O desafio do conhecimento: pesquisa qualitativa em saúde. São Paulo: Hucitec; 2007.

12. Lemos Filho O. A normatização do direito de imagem e suas limitações. Âmbito Jurídico. 2013 [citado em 1 mar 2014];16(108). Disponível em: http://www.ambito-

juridico.com.br/site/?n link=revista artigos leitu ra\&artigo id $=12670$

13.Brasil. Lei № 8.069, de 13 de julho de 1990. Dispõe sobre o Estatuto da Criança e do Adolescente e dá outras providências. Diário Oficial da União. 16 jul 1990.

14.Ministério da Saúde (BR). Secretaria de Atenção à Saúde. Núcleo Técnico da Política Nacional de Humanização. HumanizaSUS: documento base para gestores e trabalhadores do SUS. Brasília, DF: Ministério da Saúde; 2013[citado em 8 jun 2017]. (Série B. Textos básicos de saúde]. Disponível em: http://bvsms.saude.gov.br/bvs/publicacoes/hum anizasus gestores trabalhadores sus 4ed.pdf 
15.Ekra EMR, Gjengedal E. Being hospitalized with a newly diagnosed chronic illness: a phenomenological study of children's lifeworld in the hospital. Int J Qualitative Stud Health Wellbeing. 2012;7: 10.3402/qhw.v7i0.18694. https://doi.org/10.3402/qhw.v7i0.18694

16.Strasburg AC, Pintanel AC, Gomes GC, Mota MS. Cuidado de enfermagem a crianças hospitalizadas: percepção de mães acompanhantes. Rev Enferm UERJ online. 2011[citado em 13 jan 2015];19(2):262-7. Disponível em: http://www.facenf.uerj.br/v19n2/v19n2a15.pdf

17.Ferreira SL, Oliveira LMAC, Barbosa MA, Siqueira KM, Peixoto MKAV. Reflexos da hospitalização da criança na vida do familiar acompanhante. Rev Bras Enferm online. 2013;66(4):473-8.

http://dx.doi.org/10.1590/50034-

\section{2}

18.Agência Nacional de Vigilância Sanitária (ANVISA). Resolução - RDC no 50, de 21 de fevereiro de 2002. Dispõe sobre o Regulamento Técnico para planejamento, programação, elaboração e avaliação de projetos físicos de estabelecimentos assistenciais de Saúde. Diário Oficial União. 20 mar 2002.

19.Associação Brasileira de Normas Técnicas (ABNT). NBR no 9050:2004. Acessibilidade a edifícios, mobiliários, espaços e equipamentos urbanos. São Paulo: Associação Brasileira de Normas Técnicas; 2004.

20.Ferreira NAS, Esmeraldo JD, Blake MT, Antão JYFL, Raimundo RD, Abreu LC. Social representation of the hospital ludic: look of the child. Rev Bras Crescimento Desenvolv Hum online. 2014[citado em 24 fev 2015];24(2):18894. Disponível em: http://pepsic.bvsalud.org/pdf/rbcdh/v24n2/pt 1 1.pdf

21.Brasil. Lei no 11.104, de 21 de março de 2005. Dispõe sobre a obrigatoriedade de instalação de brinquedotecas nas unidades de saúde que ofereçam atendimento pediátrico em regime de internação. Diário Oficial União. 22 mar 2005.

22.Linge L. Magical attachment: children in magical relations with hospital clowns. Int J Qual Stud Health Well-being. 2012;7. https://doi.org/10.3402/qhw.v7i0.11862

23.Bishop $\mathrm{K}$. The role of art in a paediatric healthcare environment from children's and young people's perspectives. Procedia Soc Behav Sci. 2012;38:81-8. https://doi.org/10.1016/i.sbspro.2012.03.327
24.Ebneshahidi M, Hojjat I, Tabaeian SM, Mazaheri T. The study of environmental needs of patients and disabled persons with 6 to 12 years old based on their experiences, to increase the quality of pediatric-treatment spaces in Isfahan city: aphenomenological study. J Res Rehabil Sci. 2011 [citado em 26 fev 201526];7(4):488-98. Disponível em: http://en.journals.sid.ir/ViewPaper.aspx?ID=2559 $\underline{4}$ 25.Boff L. O cuidado necessário: na vida, na saúde, na ecologia, na ética e na espiritualidade. Petrópolis: Vozes; 2012.

Nota: artigo elaborado a partir da tese "Ambiente como ferramenta para a humanização da unidade pediátrica: contribuições de enfermagem" apresentado ao Programa de Pós-Graduação em Enfermagem, Universidade Federal do Rio Grande / FURG. Rio Grande - RS, Brasil. 2015.

Recebido em: 08/06/2017

Aprovado em: 22/01/2018

Endereço de correspondência: Juliane Portella Ribeiro Rua Alberto Rosa - no 001 - Centro CEP: 96010-610 - Pelotas/RS - Brasil E-mail: ju ribeiro1985@hotmail.com 